\title{
Research Achievements in Relation to Maize (Zea mays L) Crop Pro- duction and Productivity in Ethiopia: A Systematic Review
}

\author{
Dessalegn Ayana* \\ Department of Plant Science, College of Agriculture and Natural Resources, Assosa University, Assosa, Ethiopia
}

\section{ARTICLE INFO}

Article history

Received: 17 June 2021

Accepted: 15 July 2021

Published Online: 31 July 2021

Keywords:

Research achievements

Maize

Production and productivity

\section{Introduction}

Maize (Zea mays L.) is one of the most important cereal crops in the world. It ranks third position among other cereals after wheat and rice ${ }^{[1]}$. According to FAOSTAT ${ }^{[2]}$, 690.7 million tons of maize was produced on 135.4 million hectares world widely, with a yield of over 5.1 tons per hectare in the year 2012/2013. Maize is also important cereal crop in eastern and southern Africa that accounts for over $29 \%$ of the total harvested area of annual food crops and $25 \%$ of total caloric consumption.

Maize is the second most widely cultivated crop in Ethiopia ${ }^{[3]}$. In most of the regions of Ethiopia, soils are deficient in phosphorus $(\mathrm{P})$ and nitrogen $(\mathrm{N})$. In some place of Western Ethiopia, adverse soil acid prevails, and frequently combination of the limit crop production. The

\begin{abstract}
Despite the conducting much number of maize researches in different centers a little change on production and productivity in Ethiopia. Hence this review aimed to indicate how a maize production and productivity have been developed and used to inform that food security concern body of the country. I researched for different papers reporting maize production achievements, databases of peer review journal articles, scholar Google and other web sites. A total of 70 papers were reviewed from which 20 papers are included and from this $51.2 \%$ describe about maize production, $34.6 \%$ describe about productivity of a crop per area and $14.2 \%$ describe about deficiency of agricultural input utilization by local farmers. The use of new crop variety and artificial fertilizers is relatively a wide spread throughout the country. However, practical application on small holder's field has less technical support and comparatively traditional way of crop managements have been involved. Most of the research findings, particularly those from agronomic practices, indicated that Maize has wide flexibility that is suitable for production.
\end{abstract}

situation has been further aggravated by the long history of cultivation without any $\mathrm{P}$ and $\mathrm{N}$ replenishment, which led to low soil fertility and result in low crop yield.

Weed infestation is the other constraints of maize production in Ethiopia that are responsible for low maize grain yield. Worldwide maize production is hampered up to $40 \%$ by competition from weeds which are the most important pest group of this crop ${ }^{[4]}$. Generally, weeds reduce crop yield by competing for light, nutrient, water, and carbon dioxides as well as interfering with harvesting and increasing the cost involved in production. Overall weeds impose the highest loss potential (37\%) which is higher than the loss potential due to animal pest $(18 \%)^{[5]}$. A review was carried out on maize crop production and productivity. Moreover, agronomic research such as fertilizer rate and time of application, plant population density and weed management of maize

*Corresponding Author:

Dessalegn Ayana,

Department of Plant Science, College of Agriculture and Natural Resources, Assosa University, Assosa, Ethiopia;

Email: ayanadessalegn074@gmail.com 
production comprises the major components of the agronomic research undertaken by different research centers to improve production and productivity of maize in the country. The objective of this paper is to review research findings and to identify the gaps, and putting future research direction in relation to improving cultural practices for production of maize in Ethiopia.

\section{Methods}

This review followed Reporting of Central Statistical Agency (CSA), and FAOSTAT data bases are taken as bench mark. The papers were extracted into a data extraction system. This include information about author, publication date, the type of intervention and out comes in relation to research achievements of maize crop, and the use of research design, implementation and evaluation of the intervention and the influence of context of the research study in Ethiopia. Following the search of databases of peer-reviewed journal articles, the title, and abstract of the search result from peer-reviewed papers and relevant portions were reviewed. The peer-reviewed journal articles, titles, and abstracts are screened for the inclusion or exclusion purposes. The papers were compared, evaluated, and summarized narratively in relation to review. Due to the heterogeneity of the study design, implementations, and outcomes detail analysis was not conducted in this review.

\section{Results and Discussions}

A total of 70 papers were reviewed from which 20 papers are included and from this $51.2 \%$ describe about maize production, $34.6 \%$ describe about productivity of a crop per area and $14.2 \%$ describe about deficiency of agricultural input utilization by local farmers.

\subsection{Research achievements in Ethiopia}

Maize research in Ethiopia has gone through a number of changes over the last several years, which marked critical period in terms of driving the current changes in production and productivity. Some of the key events that warrant specific methods include the 1984 major drought and famine that helped to increase the profile of maize in attaining national food security. The introduction of national developed hybrids adapted the local production condition in the late 1980s and early 1990s and the introduction of an integrated system approached for research and development by the Ethiopian Institute of Agricultural research in the early $2000 \mathrm{~s}{ }^{[6]}$. It is interesting to see that the gradual increases in maize production in Ethiopia resulted more from increases in productivity rather than area expansion Figure 1.

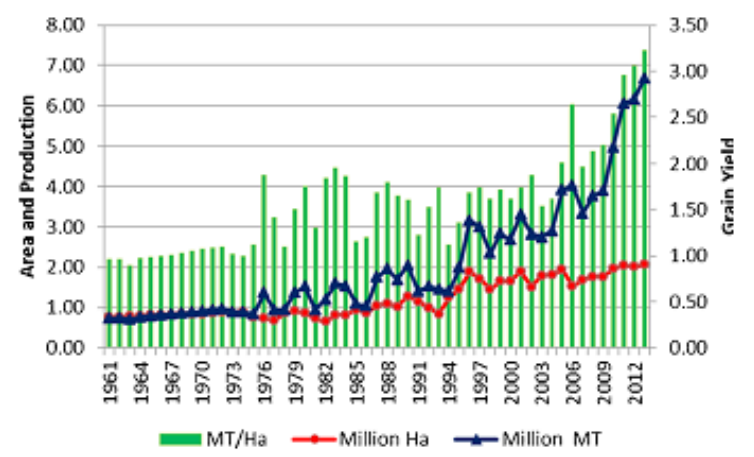

Figure 1. the lines $\mathrm{Y} 1$ axis) represent area and whereas the yield represent (Y2-axis) is represent by the bar

According to Figure 1 the increase in population growth supports the competitiveness of maize crop and area of production in Ethiopia also increases during increase in time. This increase in area come mainly from two sources. First, the traditionally sorghum growing smallholder farmers in the rift valley of Ethiopia shifted to maize, and the second maize area increase was the adoption of maize by the traditionally tef growing farmers in northern central area of Ethiopia particularly in West Gojjam, North Gondar, and others.

\subsection{Tillage and fertilizer management}

According to Asresie report for reduced tillage practices, the soil should be distributed only to place the seed and fertilizer in the soil at the time of sowing the seed by using row method of planting ${ }^{[7]}$. Thus, land preparation to suppress weed infestation is not a concern rather it is disturbed only to place the seed and fertilizer. According to the variability of the size and the farming system of the different regions of Ethiopia, different regions have different consumption trends. Of all the region four administration regions (Oromia, Amhara, SNNP, and Tigray) consumed on average more than $94.80 \%$ of fertilizer in Ethiopia. From the four regions again, consumption is in the order of Oromia $>$ Amhara $>$ SNNP $>$ Tigray and the percentage share of these regions is $36.6 \%$, $35.8 \%, 15.5 \%$ and $6.9 \%$ respectively.

Based on CSA data for 2004 to 2013 it was estimated that about fertilizer in Ethiopia are marketed as DAP (Di-ammonium-Phosphate) and urea. Potassium fertilizers are not considered to be important in Ethiopian agriculture, as there is apperception that Ethiopian soils are not deficient in potassium element.

The following figure shows that, on average DAP accounts for about $64 \%$ of the total volume of fertilizer used with urea accounting for about remaining $36 \%$. They converted the two products into $\mathrm{N}$ and $\mathrm{P}$ equivalent and 
report here the total $\mathrm{N}$ and $\mathrm{P}$ consumptions, the area fertilized and application rates. Therefore, the ratio of DAP to Urea is not the recommendable ratio 2:1 for increasing of maize production.

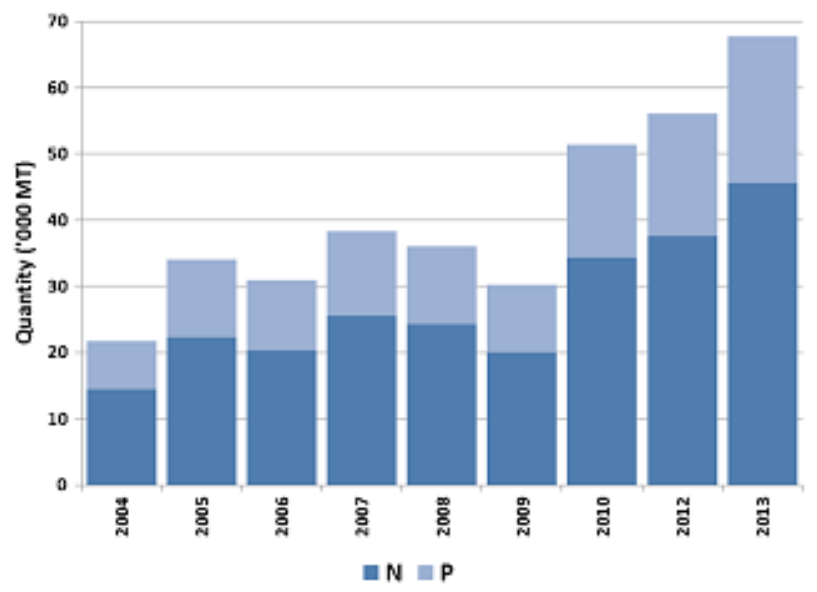

Figure 2. the overall Nitrogen and Phosphate fertilizer consumption by maize in Ethiopia between 2004 and 2013 Source: ${ }^{[8]}$

The above data shows that DAP are being gradually substituted by NPS in the recent years to meet the sulfur demand of most of Ethiopian soils.

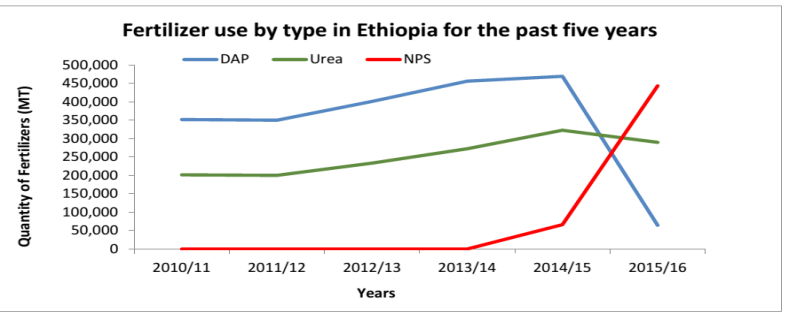

Figure 3. Fertilizer use in Ethivopia recent time ${ }^{[9]}$.

\subsection{Plant population and spacing}

Plant density is one of the most important cultural practices determining grain yield, as well as other important agronomic contributes of the crop. Plant density affects plant architecture, alters growth and developmental patterns and influences carbohydrate production and partitioning ${ }^{[10]}$.

Maize is more sensitive to variation in plant density than other members of the grass family ${ }^{[1]}$. At low densities, many modern maize hybrids do not tillers effectively and quite often produce only one ear per plant. Therefore, maize does not share the traits of most tiller grasses of compensating for low leaf area and small number of productive unit by branching ${ }^{[12]}$. On the other hand, the use of high population heightens interplant competition for light, water, and nutrients. This may be detrimental for final yield, because it stimulates apical dominance, induces barrenness, and ultimately decreases the number of ears produced per plant and kernels set per ear ${ }^{[13]}$. The spacing between stands per hectare, in turn, determines the numbers of plants per stands per hectare ${ }^{[14]}$. The number of stands per hectare, and the number of plants per stand together determine the number of plants per hectare, or the plant density. A number of factors also influence plant density: fertility status of the soil, moisture supply, growth pattern of the crop and cultural practices ${ }^{[15]}$.

Anoma ${ }^{[16]}$ reported that there was significant $(\mathrm{P}<0.05)$ main effect of varieties and Plant density, the maize gave the highest grain yield $\left(9.9 \mathrm{t} \mathrm{ha}^{-1}\right)$ at plant density of 61,538 plants per hectare Table 1 .

Table 1. Main effect of variety and plant density on above ground dry biomass, grain yield and harvest index of maize

\begin{tabular}{cccc}
\hline Treatment & BM (kgha-1) & GY $\left(\mathrm{Kgha}^{-1}\right)$ & HI (\%) \\
\hline Maize varieties & & & \\
BH-540 & $24331.1^{b}$ & $8993.7^{a}$ & $37.33^{a}$ \\
BH-140 & $24324.8^{b}$ & $8736.7^{a}$ & $37.33^{a}$ \\
BH QPY -545 & $27166.9^{a}$ & $8052.2^{b}$ & $30 \mathrm{~b}$ \\
LSD $(0.05)$ & 1957.1 & 584.94 & 2.86 \\
Plant density (ha-1) & & & \\
$72727(55 \mathrm{~cm} \times 25 \mathrm{~cm})$ & $28238^{a}$ & $8596.8 \mathrm{~b}^{c}$ & $30.69^{d}$ \\
$61538(65 \mathrm{~cm} \times 25 \mathrm{~cm})$ & $28495^{a}$ & $9921.8^{a}$ & $35.52^{a b}$ \\
$60606(55 \mathrm{~cm} \times 30 \mathrm{~cm})$ & $26313^{a b}$ & $9192.2^{a b}$ & $36.18^{a}$ \\
$53333(75 \mathrm{~cm} \times 25 \mathrm{~cm})$ & $24272^{\mathrm{bc}}$ & $8674 \mathrm{~b}^{c}$ & $35.49^{a b}$ \\
$51282(65 \mathrm{~cm} \times 30 \mathrm{~cm})$ & $23138^{d c}$ & $7882.8^{c d}$ & $34.33^{c d}$ \\
$44444(75 \mathrm{~cm} \times 30 \mathrm{~cm})$ & $21190^{d}$ & $7297.7^{d}$ & $34.79^{c d}$ \\
LSD(0.05) & 2767.7 & 827.23 & $\mathrm{NS}^{c}$ \\
CV (\%) & 11.4 & 10.05 & 12.25 \\
\hline
\end{tabular}

Means in column within a parameter followed by the same letters are not significantly different at $5 \%$ level of significance, $\mathrm{BM}=$ biomass, $\mathrm{GY}=$ grain yield, $\mathrm{HI}=$ harvest index $\operatorname{LDS}(0.05)$ $=$ Least significant difference at $5 \%$ level; $\mathrm{CV}=$ coefficient of variation and $\mathrm{NS}=$ non- significant.

\subsection{Maize achievement in cropping systems with other crops}

The achievements of maize grain yield in 1999 and continuous maize and rotational crops in 2000 and 2002 cropping season are shown in Table $2^{[17]}$. Therefore, Maize following Niger seed produced mean grain yield advantage of 971 and $1527 \mathrm{~kg} \mathrm{ha}^{-1}$ compared to haricot bean and tef. All crop rotations produced greater yield advantage of maize compared to continuous maize. The finding was indicated that maize grain yield in 1999 and continuous maize with rotational crops in 2000 and 2002 cropping season shown variation in yield of maize. 
Maize leaf removal below the ear improved tef grain yield without reducing the maize grain yield significantly ${ }^{[18]}$. It was realized that in maize-tef association, maize has a deeper root system than tef which allows for exploitation of soil nutrients and moisture at different soil layer. It was realized that in maize-tef association, maize has a deeper root system than tef which allows for exploitation of soil nutrient and moisture at different soil layers ${ }^{[19]}$. In this study it was observed that the optional level of compatible crops depend on different factors such as variety, location, and weed population.

\subsection{Weed management in maize}

According to the finding of ${ }^{[20]}$ the maximum hundred seed weight was recorded on combination of hand weeding and hoeing and the minimum was recorded on weedy check both at Gudar and Ambo sites. Moreover, the highest grain yield was obtained from hand weeding plus hoeing and followed by plot treated with Nicosulfuron at both study sites. While the lowest grain yield was scored on weedy check. However, the data were similar approach in both sites on grain yield.

Table 2. Mean grain yield of maize in 1999 and rotational crops (2000 and 2002) and continuous maize from 2000 to 2002 of grain yield across cropping seasons.

\begin{tabular}{cccc}
\hline & & \multicolumn{3}{c}{ Yield $\left(\mathbf{k g ~ h a}^{-1}\right)$} \\
\hline maize $1999\left(\mathrm{~kg} \mathrm{ha}^{-1}\right)$ & Rotation crops & 2001 & 2002 \\
4870 & Niger seed & 742 & 734 \\
4708 & Niger seed & 749 & 664 \\
6070 & Haricot bean & 1436 & 1810 \\
5738 & Haricot bean & 1422 & 1897 \\
4697 & Tef & 356 & 396 \\
4515 & Tef & 392 & 464 \\
5567 & Continuous maize & 8270 & 5544 \\
\hline
\end{tabular}

Table 3. Average land equivalent ratio (LER) for maize-tef relay intercropping with planting pattern and leaf removals at Hawasa, Ethiopia.

\begin{tabular}{ccccc}
\hline & & \multicolumn{2}{c}{ Leaf } & removal \\
\hline planting Pattern & L1 (No of leaf removal) & L2 (No of leaf removal Below ear) & L3(No of leaf removal near to the ear & Mean \\
\hline Broadcast & 1.23 & 1.3 & 1.33 & 1.29 \\
$60 \times 37.5 \mathrm{~cm}$ & 1.2 & 1.3 & 1.35 & 1.28 \\
$75 \times 30 \mathrm{~cm}$ & 1.32 & 1.48 & 1.51 & 1.44 \\
$100 \times 22 \mathrm{~cm}$ & 1.34 & 1.5 & 1.5 & 1.45 \\
Mean & 1.26 & 14 & 1.42 & 1.36 \\
\hline
\end{tabular}

Table 4. Effect of various herbicides on 100 seed weight $(\mathrm{g})$ grain yield $\left(\mathrm{kgha}^{-1)}\right.$ and relative yield loss \%

\begin{tabular}{|c|c|c|c|c|c|c|}
\hline & Gudar & & & Ambo & & \\
\hline treatments & HSW(g) & GY $\left(\right.$ kgha $\left.^{-1}\right)$ & RYL (\%) & HSW(g) & GY $\left(\right.$ kgha $\left.^{-1}\right)$ & RYL (\%) \\
\hline Nicosulfuron & $41.53 a$ & $6883.3 a$ & $4.74 \mathrm{c} d$ & $44.67 b$ & $6883.3 a b$ & $6.31 d$ \\
\hline S-metolachlor & $42.633 a$ & $5026.4 b$ & $30.15 b$ & $41.17 c$ & $5026.4 c$ & $29.37 b$ \\
\hline Primagram & $42.833 a$ & $6259.2^{\mathrm{a}}$ & $14.52 c$ & $41.30 c$ & $6129.2 b$ & $11.80 c$ \\
\hline Hand weeding +hoeing & $45.33 a$ & $6989.8 a$ & $0.00 \mathrm{c} d$ & $49.67 a$ & $7223.1 a$ & $0.00 d$ \\
\hline weed check & $33.80 b$ & $2312.4^{\mathrm{c}}$ & $63.65 a$ & $29.80 d$ & $2612.4 d$ & $75.71 a$ \\
\hline $\operatorname{LSD}(0.05)$ & 5.19 & 921.28 & 9.79 & 3.29 & 812.36 & 5.32 \\
\hline CV $(\%)$ & 6.68 & 8.84 & 23.01 & 4.24 & 7.73 & 11.47 \\
\hline
\end{tabular}

$\mathrm{HSW}=$ hundred seed weight, $\mathrm{GY}=$ grain yield, $\mathrm{RYL}=$ relative yield loss, $\mathrm{LSD}=$ least significant difference, $\mathrm{CV}=\mathrm{coefficient}$ of variance, means within a column followed by the same letter are not significantly different at 0.05 probability level using Fisher's protected LDS test. 


\section{Conclusions}

As it has been already discussed agronomic practices, such as plant density are known to affect crop environment, which directly influence grain yield. Optimum population level should be maintained to exploit maximum natural resources including soil nutrients, sunlight, and soil moistures to ensure satisfactory yield. To overcome this resource using different intercropping systems were found to be more economically advantageous than sole cropping as the maize grower could get additional yield. It was also reviewed that, fertilizer supplement on maize specially Nitrogen and Phosphorus is significantly affect grain yield. Not only fertilizer use impose maize grain yield but also weeds management in the fields of maize is very essential for obtaining tangible yield.

\section{Future Line of Work}

The future direction of maize production is based on soil fertility status and crop responses. In addition to this, concerned body has given more emphasis on the development of maize production to reduce poverty. The production of maize is mainly handled by small-scale farmers. Consequently, its farming techniques, agronomical practices, harvesting and processing technologies have followed local and traditional knowledge. In this regard, it has still required effort, time, and resources in disseminating the appropriate skill, technologies, and knowledge, for better maize production and productivity.

\section{References}

[1] FAOSTAT, 2010. Food and Agriculture Organization Statistical Database: http// faostat.fao.org. Accessed on September 10/2017.

[2] FAOSTAT, 2013. Food and Agriculture Organization Statistical Database: http// faostat.fao.org.

[3] MOA. (2005). New agro-ecological zones of Ethiopia. Addis Ababa: Ministry of Agriculture.

[4] Chikoye D, Schulz S, Ekeleme F (2004) Evaluation of integrated weed management practices for maize in the northern Guinea savanna of Nigeria. Crop Protection 23: 895-900.

[5] Chikoye D, Udensi UE, Fontem A, Lum (2005) Evaluation of a new formulation of atrazine and metolachlor mixture for weed control in maize in Nigeria. Crop Protection 24:1016-1020.

[6] Abate, T. (2007). Focusing agricultural research to address development needs: Direction for agricultural research in Ethiopia. Addis Ababa: EIAR.

[7] Asresie Hassen, Molla Tafere, Mekonen Tolla, Abel Ahmed, Seferew Dagnew, Yihenew G.Selassie,
Desallegn Molla and Alemu Worku .2015. Best fit practice on reduced tillage for maize production BDU-CASCAPE Technical working paper no 9.

[8] Central Statistical Agency (CSA). 2013. Area and production of major crops. Agricultural sample survey2012/13, private, peasant holdings, Meher season, Statistical Bulletin 532, Addis Ababa, Ethiopia.

[9] Central Statistics Agency (CSA). 2014.Agricultural sample survey report onprivate peasant holdings, meher season 2013/20014 VOLUME I, Addis Abeba, Ethiopia.

[10] Casal, J.J., Deregibus, V.A.and Sánchez, R.A., 1985. Variations in tiller dynamics and morphology in Lolium multiflorum Lam. vegetative and reproductive plants as affected by differences in red/far-red irradiation. Annals of Botany, 56:533-559.

[11] Vega, C. R. C., Andrade, F. H. and Sadras, V. O. 2001. Reproductive partitioning and seed set efficiency in soybean, sunflower and maize. Field Crop Research, 72: 165-173.

[12] Gardner, F.P., Pearce, R.B. and Mitchell, R.L., 1985. Physiology of crop plants. Ames Iowa State University.

[13] Sangoi, L. and Salvador, R.J. 1998. Influence of plant height and leaf number on maize production at high plant densities. Pesquisa Agropecuária Brasileira, 33:3, pp.297-306.

[14] Onwueme, I. C. and Sinha, T. D. 1991. Field crops production in tropical Africa. Technical Center for Agricultural and Rural Co-operation (CTA), the Netherlands. pp.159-170.

[15] Gonzalo M., T.J. Vyn, J.B. Holland and L.M. Mcintre. 2006. Mapping Density Response in Maize : A Direct Approach for Testing Genotype and Treatment Interactions. Genetics, 173 (1):331-348.

[16] Amona Tolka 2014 Effect of Varieties and Plant Density on Yield and Yield Components of Maize (Zea mays L.) in Ofa District, Gesuba, Southern Ethiopia, Msc. Thesis Haramaya Universsity, Haramaya Ethiopia.

[17] Tolera Abera1, Daba Feyisa, and D. K. Friesen (2009) Effects of Crop Rotation and N-P Fertilizer Rate on Grain Yield and Related Characteristics of Maize and Soil Fertility at Bako, Western Oromia, Ethiopia, East African Journal of Sciences 3 (1) PP 70-79.

[18] Walelign Worku. 2004. Maize-tef relay intercropping as affected by maize planting pattern and leaf removal in southern Ethiopia. African Crop Science Journal. 12(4):358 367.

[19] Wondimu Bayu, Molla Addisu, Besufekad Tadesse and Legesse Admassu, 2007. Intercropping tef and sunflower in semi-arid areas of Wello, Ethiopia. Trop. Sci., 47(1): 16-21.

[20] Tesfay A, Amin M, Mulugeta N (2014) Management of Weeds in Maize (Zea maysL.) through Various Pre and Post Emergency Herbicides. Adv Crop Sci Tech 2: 151. 